\title{
Sociodemographic and Other Characteristics Associated With Behavioural Risk Factors of HIV Infection Among Male Mountain-Climbing Porters in Kilimanjaro Region, Tanzania
}

\author{
Jenipher E Lyamuya, ${ }^{1}$ Bernard Njau, ${ }^{2}$ Damian J Damian, ${ }^{2}$ Tara B Mtuy ${ }^{2,3}$ \\ ${ }^{1}$ African Medical and Research Foundation, Moshi, Tanzania; ${ }^{2}$ Kilimanjaro Christian Medical University College, Moshi, Tanzania; ${ }^{3}$ London School of Hygiene \& \\ Tropical Medicine, London, UK \\ Correspondence to Tara Mtuy (tara.mtuy@lshtm.ac.uk).
}

\section{ABSTRACT}

Background: Alcohol consumption, marijuana use, unprotected sex, and multiple concurrent sexual partnerships are prevalent among youth globally. These factors are regarded as important behavioural risk factors for HIV infection. The aim of this study was to assess the sociodemographic and other characteristics associated with behavioural risk factors of HIV infection among male mountain-climbing porters working on Mount Kilimanjaro in Tanzania.

Methods: This cross-sectional study enrolled a representative sample of 384 male mountain-climbing porters from 7 tour companies in the Kilimanjaro region using a multi-stage sampling technique. Local interviewers completed a structured questionnaire with porters in the local language, Kiswahili. The questionnaire covered demographics, alcohol and marijuana use, sexual history, sexual partners, and condom use. In-person interviews were completed between April and May 2013. Univariate and bivariate analysis were used to describe data and determine significant predictors of behavioural risk factors of HIV infection.

Results: Of 384 participants, 381 (99.2\%) were sexually experienced, 353 (92.6\%) were sexually active, and $168(44.1 \%)$, reported condom use at last sex. The prevalence of ever-use of alcohol was $62 \%$, and $68 \%$ of participants reported being current alcohol users. The prevalence of ever-use of marijuana was $15 \%$, and $49 \%$ of participants reported being current marijuana users, with $12 \%$ reporting daily use. Age, marital status, working duration as a porter, transactional sex practices, and number of concurrent sexual partners were factors that were significantly associated with unprotected sex, alcohol consumption, and marijuana use $(P<.05)$.

Conclusions: Age, marital status, working duration, transactional sex practices, and number of concurrent sexual partners were significantly associated with unprotected sex, alcohol consumption, and marijuana use, among porters in this setting. The findings suggest the need for efforts to motivate sexually active male porters to engage in HIV prevention interventions, including condom use and reduction of multiple concurrent sexual partners, transactional sexual practices, alcohol consumption, and marijuana use.

\section{INTRODUCTION}

$\mathbf{H}$ IV and AIDS remain a worldwide global health problem with an estimated 36 million people living with HIV globally. ' Sub-Saharan Africa is the region most affected by HIV/AIDS, contributing $75 \%$ of the global HIV burden. ${ }^{1}$ Preventing and controlling HIV/AIDS among youth aged 15-24 years is a current global challenge. According to the United Nations Population Fund (UNFPA), the youth population has surpassed 1 billion globally-the largest in human history. $^{2}$ In Tanzania, almost two-thirds (65\%) of the population is under the age of 24 years, and youth are affected most by HIV/AIDS with an overall prevalence of $7.9 \%$. $^{3,4}$

One of the major drivers of the high HIV prevalence among youth is early sexual activity. For example, a substantial proportion $(85 \%)$ of unmarried youth in Tanzania are sexually experienced with low (12.2\%) condom-use practices. $^{5}$ Alcohol consumption and marijuana use are also becoming a major global public health problem, particularly among youth. According 
to the World Health Organization (WHO), alcohol consumption and marijuana use contribute $4 \%$ of the disabilityadjusted life years of the global burden of disease. ${ }^{6-9}$ In subSaharan Africa, approximately $25 \%$ of young people are current drinkers and reported to consume 35 litres of pure alcohol annually. ${ }^{10,11}$ In Tanzania, the proportion of substance use, including alcohol consumption, is increasing, with $17.2 \%$ of urbanite youth current users. ${ }^{10}$ The high alcohol consumption among youth is compounded with risky sexual behaviours, such as multiple concurrent sexual partnerships and low or inconsistent condom use. ${ }^{10}$

In Kilimanjaro region, public health officers have identified 2 high-risk populations for HIV - female bar workers and male mountain-climbing porters. While several studies in this area have documented HIV risk behaviours among female bar workers ${ }^{12,13}$ and among youth in different settings, ${ }^{5,16}$ there is limited information pertaining to risk characteristics specifically of young male mountainclimbing porters, who may share many risk characteristics with other high-risk groups, such as long-distance truck drivers, ${ }^{17,18}$ fishermen, ${ }^{19-21}$ miners, ${ }^{22,23}$ and migrant farm workers. $^{24}$

The estimated 17,000 porters of Mount Kilimanjaro are between the ages of 18 and 45 years, but are predominantly young men who are very mobile and face volatile income cycles. ${ }^{14}$ Evidence suggests that people who work in difficult environments, have seasonal jobs, and earn a higher-thanaverage living wage are at high risk of overspending money on alcohol and marijuana and are more likely to have multiple sexual partners. Such risky behaviours may lead to unsafe sex practices, posing a risk of HIV infection. ${ }^{15}$

The aim of this study was to assess the sociodemographic and other characteristics associated with behavioural risk factors of HIV infection among male mountain-climbing porters in Kilimanjaro region, Tanzania. The findings from this study will contribute to knowledge of risk characteristics of male porters of Mt. Kilimanjaro and may assist knowledge brokers, policy makers, and HIV prevention interventionists to develop effective strategies to influence behaviour change for prevention of HIV transmission among this high-risk group in this study setting.

\section{METHODS}

\section{Study Population and Protocol}

We conducted a cross-sectional study designed to assess sociodemographic and other characteristics associated with behavioural risk factors for HIV infection among male mountain-climbing porters in the Kilimanjaro region. According to a conversation with a representative from the Kilimanjaro Porters Assistance Project (February 2013), it is estimated that a total of 17,000 porters are registered with the 3 Kilimanjaro porters unions. A multistage sampling technique was used to obtain the estimated sample of participants. In the first stage, we randomly selected 7 of 14 tour companies. In the second stage, we obtained a list of all porters working in the 7 tour companies from the tour companies' management and then used sampling proportionate to size technique to select a random sample of 384 participants. Sample size calculation was based on an HIV prevalence of $50 \%$, as no other study has been done on behavioural risk factors for HIV among porters. Local interviewers were trained on obtaining informed consent, maintaining confidentiality, following interview procedures, and completing the questionnaire. Study participants, recruited between April and May 2013, completed in-person interviews in Kiswahili with the interviewers.

\section{Measures}

Alcohol use was assessed by 11 questions whereby 4 questions were adapted from CAGE questionnaire. ${ }^{25}$ Marijuana use was assessed by 6 structured questions and a composite score was calculated. Participants self-reported sociodemographic information included age, marital status, highest level of completed education, and income. Condom use was assessed by asking participants if they had had sex without a condom during the last sexual intercourse ( $1=y e s ; 2=n o$ ). A response of 'yes' indicated sexual risk behaviour. Transactional sex practices were assessed by asking participants if they had exchanged/paid/received a gift for sex during the last 6 months $(1=$ no; $2=y e s$, received; $3=y e s$, given; $4=y e s$, received and given). Number of sexual partners was assessed by asking participants the number of casual sexual partners they had during the last 3 months. The number of any sexual partners was dichotomised and coded: 'no multiple sexual partners' ( $\leq 1$ sexual partner) or 'multiple sexual partners' ( $>$ l sexual partner).

\section{Statistical Analyses}

Data were entered, cleaned, and analysed using Statistical Package for Social Science (SPSS) version 18 (SPSS, Inc., Chicago IL). Categorical data were summarised using frequency and percentages, while numerical data were summarised using measures of central tendencies with their respective measures of dispersions. Chi-square test was used to determine statistical associations between categorical variables. Bivariate logistic regression analysis was used to determine sociodemographic and other characteristics associated with behavioural risk factors of HIV infection among study participants. A $P$-value was considered statistically significant at the .05 level.

\section{Ethical Approval}

The study and all study activities were approved by the Kilimanjaro Christian Medical University College Research Ethical Review Committee. Written informed consent was obtained. Participants were informed of their voluntariness to participate and freedom to withdraw at any point from the study. 


\section{RESULTS}

\section{Background Characteristics}

Sociodemographic Characteristics

In total, 384 porters were enrolled in the study. The mean age of study participants was 31 years (standard deviation [SD], 6.6) (Table 1). More than half $(n=199,51.8 \%)$ of the study participants were married. Most $(n=247,64.3 \%)$ had primary education, and $60.2 \%$ earned an average monthly income of less than 400,000 Tanzanian Shillings (TZS) during high season (in 2012, US $\$ 1=1,600 \mathrm{TZS}$ ). More than half $(\mathrm{n}=219,57.0 \%)$ of participants had been working as a porter for 3 to 5 years.

\section{Sexual Characteristics}

Nearly all participants $(\mathrm{n}=381,99.2 \%)$ reported being sexually experienced (Table 2). Of the 381 respondents who reported being sexually experienced, 177 (46.5\%) reported having sex 1 to 6 days prior to the interview and $353(92.6 \%)$ said they had had sex during the last 3 months. More than half $(54.6 \%)$ of sexually experienced respondents had had sex with their wives. The majority $(85.8 \%)$ of participants did not report having sex in exchange for money or a gift during the last 6 months prior to the interview. Out of the 353 sexually active participants who had had sex during the last 3 months, 61 (17.3\%) reported multiple concurrent sexual partners. Of the 381 sexually experienced participants, $168(44.1 \%)$ reported condom use during their last sexual intercourse.

\section{Prevalence of Alcohol and Marijuana Use}

Of the total 384 participants, 237 (61.7\%) reported ever drinking alcohol (Table 3). Of these, $161(67.9 \%)$ reported being current drinkers. Of the 161 current drinkers, $81(50.3 \%)$ reported drinking 2 to 7 times per week and drinking on average 4 bottles (SD, 3; range, 1-25) during a typical day. The majority $(n=136,84.5 \%)$ of current drinkers reported drinking beer, and $6(3.7 \%)$ took 6 or more drinks at 1 occasion daily.

Of the 384 participants, 57 (14.8\%) reported to have ever used marijuana (Table 4). Mean age at first time using marijuana was 18 years (SD, 5.4). The youngest age reported to have started using marijuana was 7 years while the oldest age was 45 years. The prevalence of reported current marijuana use was $49.1 \%(n=28)$. Out of 28 respondents who reported current marijuana use, 12 (42.9\%) reported daily use.

\section{Sociodemographic and Other Characteristics Associated With Behavioural Risk Factors of HIV Infection Among Study Participants}

The 4 behavioural risk factors of HIV infection in this study were condom use during the last sexual intercourse, having multiple concurrent sexual partners, and use of alcohol and marijuana. Age was significantly associated with all 4 of
TABLE 1. Sociodemographic Characteristics of Respondents ( $\mathrm{N}=384)$

\begin{tabular}{|c|c|}
\hline Variable & n (\%) \\
\hline \multicolumn{2}{|l|}{ Age (years) } \\
\hline $20-29$ & $162(42.2)$ \\
\hline $30-39$ & $172(44.8)$ \\
\hline $40-49$ & $50(13.0)$ \\
\hline \multicolumn{2}{|l|}{ Level of education } \\
\hline None & $2(0.5)$ \\
\hline Primary & $247(64.3)$ \\
\hline Secondary & $126(32.8)$ \\
\hline Post-secondary & $9(2.3)$ \\
\hline \multicolumn{2}{|l|}{ Marital status } \\
\hline Married & $199(51.8)$ \\
\hline Single & $127(33.1)$ \\
\hline Cohabiting & $54(14.1)$ \\
\hline Divorced & $3(0.8)$ \\
\hline Widowed & $1(0.3)$ \\
\hline \multicolumn{2}{|l|}{$\begin{array}{l}\text { Monthly income during high season (TZS) } \\
(\mathrm{n}=383)\end{array}$} \\
\hline$<200,000$ & $86(22.4)$ \\
\hline $200,000-399,000$ & $145(37.8)$ \\
\hline $400,000-599,000$ & $69(18.0)$ \\
\hline $600,000-799,000$ & $48(12.5)$ \\
\hline $800,000+$ & $36(9.4)$ \\
\hline \multicolumn{2}{|l|}{ Duration working as a porter (years) } \\
\hline$\leq 2$ & $32(8.3)$ \\
\hline $3-5$ & $219(57.0)$ \\
\hline $6-8$ & $92(24.0)$ \\
\hline $9-11$ & $35(9.1)$ \\
\hline $12+$ & $6(1.6)$ \\
\hline $\begin{array}{l}\text { Duration of work, years, mean (standard } \\
\text { deviation) }\end{array}$ & $5.9(4.6)$ \\
\hline
\end{tabular}

these behavioural risk factors $(P<.05)$ : older participants were more likely than younger participants (20-29) to have not used condoms at last sex (30-39 year age group: odds ratio [OR] 4.60; 95\% confidence interval [CI], 
TABLE 2. Sexual Characteristics of Study Participants $(\mathrm{N}=384)$

\begin{tabular}{lc}
\hline Variable (n) & $\mathbf{n}(\%)$ \\
\hline Ever had sex & \\
Yes & $381(99.2)$ \\
No & $3(0.8)$ \\
Last time had sex (381) & \\
1-6 days ago & $177(46.5)$ \\
7 days ago & $65(171.0)$ \\
1-11 months ago & $101(26.5)$ \\
$\geq 12$ months ago & $38(10.0)$ \\
Relationship to the woman with whom & \\
had last sex (381) & \\
Wife & $208(54.6)$ \\
Fiancée & $35(9.2)$ \\
Regular partner & $77(20.1)$ \\
Causal partner & $54(14.2)$ \\
Tourist & $2(0.5)$ \\
Commercial sex worker & $5(1.3)$ \\
Place you first met this woman (381) & \\
Own/friend's house & $55(14.4)$ \\
Family event & $9(2.4)$ \\
Bar/hotel & $22(5.8)$ \\
Park/company & $11(2.9)$ \\
Church & $18(4.7)$ \\
Other places & $266(69.8)$ \\
\hline & Continued \\
\hline
\end{tabular}

2.76-7.73; 40-49 year age group: OR 20.20; 95\% CI, 4.75$86.10)$ but less likely to have multiple concurrent sexual partners (OR 0.39; 95\% CI, $0.21-0.73$ vs. OR $0.61 ; 95 \%$ CI, 4.75-86.10, respectively). Similarly, older participants were more likely than younger participants to consume alcohol (OR 1.71; 95\% CI, 1.12-2.72 vs. OR 1.63; 95\% CI, 0.843.16 , respectively) and to use marijuana (OR $0.54 ; 95 \% \mathrm{CI}$, $0.30-0.99$ vs. OR $0.25 ; 95 \%$ CI, 0.07-0.85, respectively).

Marital status was significantly associated with condom use during last sexual intercourse, having multiple concurrent sexual partners, and marijuana use $(P<.05)$. Compared
TABLE 2. Continued

\begin{tabular}{lc}
\hline Variable (n) & $\mathbf{n}(\%)$ \\
\hline $\begin{array}{l}\text { In last 6 months, exchanged/paid } \\
\text { money/gift for sex (381) }\end{array}$ & \\
No & $327(85.8)$ \\
Yes, received & $7(1.8)$ \\
Yes, given & $39(10.2)$ \\
Yes, received and given & $8(2.1)$ \\
Relationship to the woman with whom & \\
paid/gave/received money/gift for sex & \\
(330) & \\
Tourist & $5(9.3)$ \\
Commercial sex worker & $12(22.2)$ \\
Bar/hotel worker & $13(24.1)$ \\
Sex partner/friend & $24(44.4)$ \\
Had multiple sexual partners in the past 3 \\
months (353) \\
Yes \\
No \\
Used condom at last sex (381) \\
Yes \\
No & $61(17.3)$ \\
\end{tabular}

with married participants, those who were single were less likely to have had unprotected sex during last sexual intercourse (OR 0.06; 95\% CI, 0.03-0.11), but were more likely to have multiple concurrent sexual partners (OR 3.27; $95 \%$ CI, 1.76-6.07) and to use marijuana (OR 5.76; $95 \%$ CI, 2.78-11.92).

In general, the longer respondents worked as a porter, the higher the likelihood of them not using condoms as last $\operatorname{sex}(P<.001)$.

Receiving money or gifts for sex during the last 6 months was significantly associated with having unprotected sex during the last sexual intercourse (OR 1.49; 95\% CI, 1.112.25). In addition, receiving or giving money or gifts for sex was significantly associated with having multiple concurrent sexual partners and with marijuana use $(P<.05)$.

Furthermore, the number of any sexual partners in the past 3 months was significantly associated with unprotected sex during the last sexual intercourse $(P=.001)$. Respondents with more than 1 sexual partner were more likely not to 
TABLE 3. Prevalence of Alcohol Use Among Study Participants ( $\mathrm{N}=384)$

\begin{tabular}{lc}
\hline Variable (n) & $\mathbf{n}(\%)$ \\
\hline Ever drank alcohol (384) & \\
Yes & $237(61.7)$ \\
No & $147(38.3)$ \\
Currently drinking alcohol (237) & \\
Yes & $161(67.9)$ \\
No & $76(32.1)$ \\
Frequency of drinking (161) & \\
Monthly or less & $15(9.3)$ \\
$2-4$ times a month & $65(40.4)$ \\
2-3 times a week & $57(35.4)$ \\
$4+$ times a week & $24(14.9)$ \\
Type of alcohol (161) & $136(84.5)$ \\
Beer & $3(1.9)$ \\
Liquor & $21(13.0)$ \\
Mbege (local brew) & $1(0.6)$ \\
Both & \\
Frequency of having 6 or more drinks on & \\
1 occasion (161) & $106(65.8)$ \\
Never & $25(15.5)$ \\
Once per month & $15(9.3)$ \\
$2-3$ times per month & $9(5.9)$ \\
Weekly & $6(3.7)$ \\
Daily/almost daily & \\
Number of drinks taken on a typical day, \\
mean (standard deviation) (161)
\end{tabular}

use condoms in their last sexual intercourse (OR 1.38; 95\% CI, 0.21-0.67).

Level of income was not significantly associated with any of the 4 studied behavioural risk factors $(P>.05)$.

\section{DISCUSSION}

The study findings have shown that certain sociodemographic characteristics, as well as paying or receiving money or gifts for sex, are associated with behavioural risk factors for HIV infection among porters in Kilimanjaro region, Tanzania. Overall, the majority of porters were sexually
TABLE 4. Prevalence of Marijuana Use Among Study Participants ( $\mathrm{N}=384)$

\begin{tabular}{ll}
\hline Variable (n) n (\%) \\
\hline
\end{tabular}

Ever used marijuana (384)

Yes $57(14.8)$

No $327(85.2)$

Currently using marijuana (57)

Yes

$28(49.1)$

No

$29(50.9)$

Age first started using marijuana (57)

$\leq 10$

$11-20$

$42(73.7)$

21-30

$11(19.3)$

$31-40$

$41+$

Usual frequency of using marijuana (28)

Every day

2-3 times a week

2-3 times a month

$5(17.9)$

Once in a month

$2(7.1)$

experienced, more than half $(56 \%)$ reported they did not use a condom during their last sexual intercourse, and almost one-fifth $(17 \%)$ reported having multiple concurrent sexual partners.

Overall, older respondents were more likely to have not used condoms, so unprotected sex increased with increasing age, but the likelihood of having multiple concurrent sexual partnerships decreased with increasing age. The most probable explanation to these observations may be due to the fact that young male porters tend to use condoms because they also engage in multiple concurrent sexual partnerships, hence perceive themselves being at high risk of HIV infection..$^{5,26,27}$ In contrast, older male porters are less likely than older porters to use condoms because they may be in a regular sexual partnership. Additionally, this observation of high condom use among younger participants can possibly be due to exposure to sensitisation messages on condom use. ${ }^{4}$ This finding is in contrast with findings from previous investigators on youth's sexual activity in Tanzania, who found that condom use was higher among older respondents. ${ }^{4,16}$ 
TABLE 5. Sociodemographic Characteristics Associated With Behavioural Risk Factors for HIV Among Study Participants $(\mathrm{N}=384)$

\begin{tabular}{|c|c|c|c|c|c|}
\hline \multirow[b]{2}{*}{ Characteristics } & \multirow[b]{2}{*}{$\begin{array}{c}\text { Total } \\
\text { (n) }\end{array}$} & \multicolumn{4}{|c|}{ Behavioural Risk Factors } \\
\hline & & $\begin{array}{l}\text { Did Not Use Condom } \\
\text { During Last Sex } \\
\text { OR }(95 \% \mathrm{Cl})\end{array}$ & $\begin{array}{l}\text { Had Multiple Concurrent } \\
\text { Sexual Partner } \\
\text { OR }(95 \% \mathrm{Cl})\end{array}$ & $\begin{array}{l}\text { Use Alcohol } \\
\text { OR (95\% Cl) }\end{array}$ & $\begin{array}{l}\text { Use Marijuana } \\
\text { OR (95\% CI) }\end{array}$ \\
\hline \multicolumn{6}{|l|}{ Age (years) } \\
\hline $20-29$ & 162 & 1 & 1 & 1 & 1 \\
\hline $30-39$ & 172 & $4.60(2.76,7.73)$ & $0.39(0.21,0.73)$ & $1.71(1.12,2.72)$ & $0.54(0.30,0.99)$ \\
\hline $40-49$ & 50 & $20.20(4.75,86.10)$ & $0.61(4.75,86.10)$ & $1.63(0.84,3.16)$ & $0.25(0.07,0.85)$ \\
\hline \multicolumn{6}{|l|}{ Marital status } \\
\hline Married & 199 & 1 & 1 & 1 & 1 \\
\hline Single & 127 & $0.06(0.03,0.11)$ & $3.27(1.76,6.07)$ & $1.01(0.64,1.50)$ & $5.76(2.78,11.92)$ \\
\hline Cohabiting & 54 & $0.47(0.20,1.12)$ & $1.67(0.72,3.89)$ & $1.32(0.70,2.48)$ & $5.42(2.27,12.95)$ \\
\hline Divorced/widowed & 4 & $0.19(0.02,2.17)$ & $4.00(0.35,45.94)$ & $\mathrm{NC}$ & $8.55(0.72,10.66)$ \\
\hline \multicolumn{6}{|l|}{$\begin{array}{l}\text { Monthly income during high } \\
\text { season (TZS) }\end{array}$} \\
\hline$<200,000$ & 86 & 1 & 1 & 1 & 1 \\
\hline $200,000-399,000$ & 145 & $1.60(0.65,3.90)$ & $0.68(0.22,2.12)$ & $1.62(0.69,3.78)$ & $1.55(0.42,5.71)$ \\
\hline $400,000-599,000$ & 69 & $1.36(0.58,3.16)$ & $0.79(0.27,2.29)$ & $0.95(0.86,4.40)$ & $1.60(0.45,5.67)$ \\
\hline $600,000-799,000$ & 48 & $2.52(0.81,7.84)$ & $1.04(0.29,3.75)$ & $1.99(0.72,5.47)$ & $0.71(0.13,3.80)$ \\
\hline $800,000+$ & 36 & $3.43(1.07,11.01)$ & $1.16(0.34,3.97)$ & $1.68(0.63,4.49)$ & $1.11(0.24,5.09)$ \\
\hline \multicolumn{6}{|l|}{$\begin{array}{l}\text { Duration working as a porter } \\
\text { (years) }\end{array}$} \\
\hline$\leq 2$ & 32 & 1 & 1 & 1 & 1 \\
\hline $3-5$ & 219 & $2.61(1.48,4.60)$ & $1.19(0.54,2.59)$ & $1.83(1.07,3.14)$ & $0.54(0.26,1.15)$ \\
\hline $6-8$ & 92 & $3.68(1.76,7.70)$ & $1.31(0.54,3.18)$ & $4.14(2.03,8.44)$ & $0.92(0.40,2.10)$ \\
\hline $9-11$ & 35 & $4.24(1.77,10.13)$ & $1.71(0.67,4.36)$ & $1.36(0.67,2.76)$ & $0.63(0.23,1.72)$ \\
\hline $12+$ & 6 & $4.03(1.65,9.83)$ & $0.33(0.07,1.58)$ & $4.03(1.65,9.83)$ & \\
\hline \multicolumn{6}{|l|}{$\begin{array}{l}\text { In last } 6 \text { months, exchanged/ } \\
\text { paid money/giff for sex }\end{array}$} \\
\hline No & 327 & 1 & 1 & 1 & 1 \\
\hline Yes, received & 7 & $1.49(1.11,2.25)$ & $3.35(1.62,17.97)$ & $0.49(0.11,2.25)$ & $2.79(1.52,14.85)$ \\
\hline Yes, given & 39 & $1.91(0.90,4.06)$ & $11.52(5.49,24.16)$ & $1.91(0.90,4.06)$ & $3.10(1.46,6.59)$ \\
\hline Yes, received and given & 8 & $1.10(0.26,4.68)$ & $13.96(3.19,61.17)$ & $1.10(0.26,4.68)$ & $0.99(0.12,8.31)$ \\
\hline \multicolumn{6}{|c|}{$\begin{array}{l}\text { Number of any sexual partner } \\
\text { in the past } 3 \text { months }\end{array}$} \\
\hline$\leq 1$ & 292 & 1 & - & 1 & 1 \\
\hline More than one & 61 & $1.38(1.21,0.67)$ & - & $1.51(0.83,2.74)$ & $1.99(1.00,3.96)$ \\
\hline Total & & $73.0 \%(n=278)$ & $17.3 \%(n=61)$ & $61.7 \%(n=237)$ & $14.8 \%(n=57)$ \\
\hline
\end{tabular}

Abbreviations: $\mathrm{Cl}$, confidence interval; $\mathrm{NC}$, not calculated; OR, odds ratio. 
Marital status was associated with unprotected sex, multiple concurrent sexual partnerships, and marijuana use. The likelihood of condom use was higher among unmarried participants than their married counterparts. Furthermore, unmarried participants were more likely to have multiple concurrent sexual partners and to smoke marijuana. This finding is consistent with behavioural studies assessing motivating factors associated with condom use among youth, which found that respondents who perceived higher susceptibility to HIV infection through their risky behaviours were more likely to report condom use..$^{5,16}$

Transactional sex was associated with unprotected sex, having multiple concurrent partners, and marijuana use. Porters who reported to have paid and/or received money or a gift in exchange for sex were more likely to report unprotected sex and to smoke marijuana. The finding that transactional sexual practice was associated with unprotected sex is consistent with several studies among youth in different settings. Existing evidence on HIV infection in sub-Saharan Africa shows that transactional and transgender sexual practices are 2 major drivers for the high HIV prevalence in the general population, including youth. ${ }^{1}$ Additionally, the observed risk behaviour of mixing unprotected sexual practices and marijuana smoking underscores the importance of skills development for safer sex among porters in this setting. An intervention designed to increase motivation for condom use while addressing the mixed-risk behaviours may be an effective approach. $^{1,28,29}$

Finally, the number of concurrent sexual partners in the last 3 months was associated with non-condom use among porters. Porters who reported more than 1 concurrent sexual partner during their last sexual intercourse were more likely to engage in unprotected sex. This observation is consistent with studies on condom use among youth, ${ }^{1,30,31}$ and raises concern that porters in this setting are at high risk of contracting HIV. Indeed, low rates of condom use coupled with high rates of multiple concurrent sexual partners may increase the spread of HIV among male porters.

\section{Limitations}

Although this study addressed a number of behavioural risk factors associated with HIV infection among Kilimanjaro mountain porters, some risk factors were not explored. This included knowledge of HIV transmission and prevention, sexual practices, HIV status, and history of other sexually transmitted diseases. Further studies addressing these risk factors are important to better understand this at-risk population for HIV.

This study has other certain limitations. First, the crosssectional study design that we used is not adequate for measuring the directionality of associations found and, therefore, cannot account for potential confounders. Second, we asked respondents to recall events that had occurred in the distant past. Recall bias may be a limitation, particularly among older porters who may be unable to remember the exact timing of their early sexual activities. Third, the study relied on self-reports. It is known that the self-reported behaviour is subject to reporting bias, which may overestimate or underestimate the effects of association and the validity of the findings. In particular, due to marijuana use being illegal in Tanzania, it was likely underreported. Finally, given that this study was conducted in a particular location and among male porters, it may not be applicable to other settings or the general population. Nevertheless, the study findings provide an important insight into male mountain climbing porters' behavioural risk factors for HIV infection.

\section{REFERENCES}

1. Joint United Nations Programme on HIV/AIDS (UNAIDS). How AIDS Changed Everything -MDG 6: 15 Years, 15 Lessons of Hope from the AIDS Response. Geneva: UNAIDS; 2015.

2. United Nations Population Fund (UNFPA). Youth and HIV/AIDS fact sheet: state of the world population. New York: UNFPA; 2009.

3. National Bureua of Statistics, Office of Chief Government Statistician. 2012 Tanzania Population and Housing Census. Dar es Salaam and Zanzibar, Tanzania: Ministry of Finance and President's Office, Finance, Economy, and Development Planning; 2012.

4. Tanzania Commission for AIDS (TACAIDS), Zanzibar AIDS Commission (ZAC), National Bureau of Statistics (NBS), Office of the Chief Government Statistician (OCGS), and ICF International. Tanzania HIV/AIDS and Malaria Indicator Survey 2011-12. Dar es Salaam, Tanzania: TACAIDS, ZAC, NBS, OCGS, and ICF International; 2013.

5. Katikiro $E$, Njau B. Motivating factors and psychosocial barriers to condom use among out-of-school youths in Dar es Salaam, Tanzania: a cross sectional survey using the health belief model. ISRN AIDS. 2012;2012:170739. CrossRef. Medline

6. World Health Organization (WHO). Global Status Report on Alcohol and Health. Geneva: WHO; 2001.

7. World Health Organization (WHO). Global Status Report on Noncommunicable Diseases. Geneva: WHO; 2011.

8. Ezzati M, Lopez AD, Rodgers A, Murray CJL, eds. Comparative Quantification of Health Risks. Global and Regional Burden of Disease Attributable to Selected Major Risk Factors. Geneva: World Health Organization; 2004.

9. Rehm J, Taylor B, Room R. Global burden of disease from alcohol, illicit drugs and tobacco. Drug Alcohol Rev. 2006;25(6):503-513. CrossRef. Medline

10. Mbatia J, Jenkins R, Singleton N, White B. Prevalence of alcohol consumption and hazardous drinking, tobacco and drug use in urban Tanzania and their associated risk factors. Int J Environ Res Public Health. 2009;6(7):1991-2006. CrossRef

11. United Nations International Drug Control Programme (UNDCP), World Health Organization (WHO). Substance Abuse in Southern Africa. Geneva; WHO; 2003.

12. Ao TT, Sam NE, Masenga EJ, Seage GR 3rd, Kapiga SH. Human immunodeficiency virus type 1 among bar and hotel workers in northern Tanzania: the role of alcohol, sexual behavior, and herpes simplex virus type 2. Sex Transm Dis. 2006;33(3):163169. CrossRef. Medline

13. Kapiga SH, Sam NE, Shao JF, et al. HIV-1 epidemic among female bar and hotel workers in northern Tanzania: risk factors and opportunities for prevention. J Acquir Immune Defic Syndr. 2002;29(4):409-417. CrossRef. Medline

14. Peaty D. Kilimanjaro tourism and what it means for local porters and for the local enviroment. J Ritsumeikan Soc Sci Human. 2010;4:1-12. 
15. Simkhada P, vanTeijlingen ER, Regmi PR, Bhatta P. Sexual health knowledge, sexual relationships and condom use among male trekking guides in Nepal: a qualitative study. Cult Health Sex. 2010;12(1):37-41. CrossRef

16. Njau B, Mwakalo V, Mushi D. Correlates of use of condoms among sexually active youth in Southern Highlands, Tanzania. SAGE Open. 2013;3(2):1-9. CrossRef

17. Deane KD, Parkhurst JO, Johnston D. Linking migration, mobility and HIV. Trop Med Int Health. 2010;15(12):1458-1463. CrossRef. Medline

18. Delany-Morettwe S, Bello B, Kinross $P$, et al. HIV prevalence and risk in long-distance truck drivers in South Africa: a national cross-sectional survey. Int J STD AIDS. 2014;25(6):428-438. CrossRef. Medline

19. Kiwanuka N, Ssetaala A, Nalutaaya A, et al. High incidence of HIV-1 infection in a general population of fishing communities around Lake Victoria, Uganda. PLoS One. 2014;9(5):e94932. CrossRef. Medline

20. Kwena ZA, Bukusi EA, Ngayo MO, et al. Prevalence and risk factors for sexually transmitted infections in a high-risk occupational group: the case of fishermen along Lake Victoria in Kisumu, Kenya. Int J STD AIDS. 2010;21(10):708-713. CrossRef. Medline

21. Smolak A. A meta-analysis and systematic review of HIV risk behavior among fishermen. AIDS Care. 2014;26(3):282-291. CrossRef. Medline

22. Cliff $S$, Anemona A, Watson-Jones $D$, et al. Variations of HIV and STI prevalences within communities neighbouring new goldmines in Tanzania: importance for intervention design. Sex Transm Infect. 2003;79(4):307-312. CrossRef. Medline

23. Desmond N, Allen CF, CliftS, et al. A typology of groups at risk of HIV/STI in a gold mining town in north-western Tanzania. Soc Sci Med. 2005;60(8):1739-1749. CrossRef. Medline

24. Heffron R, Chao A, Mwinga A, et al. High prevalent and incident HIV-1 and herpes simplex virus 2 infection among male migrant and non-migrant sugar farm workers in Zambia. Sex Transm Infect. 2011;87(4):283-288. CrossRef. Medline

25. Ewing, J.A. Detecting alcoholism: The CAGE questionnaire. JAMA. 1984;252:1905-1907. Medline
26. Lawoyin $\mathrm{OO}$, Kanthula RM. Factors that influence attitudes and sexual behavior among constituency youth workers in Oshana Region, Namibia. Afr J Reprod Health. 2010;14(1):55-69. Medline

27. Champion VL, Skinner CS. The Health Belief Model. In: Glanz K, Rimer BK, eds. Health Behavior and Health Education: Theory, Research and Practice. San Francisco: Jossey-Bass; 2008:45-65.

28. Outlaw A, Naar-King S, Janisse H, Parsons JT; Adolescent Trials Network for HIV/ AIDS Interventions. Predictors of condom use in a multisite study of high-risk youth living with HIV. AIDS Educ Prev. 2010;22(1):1-14. CrossRef. Medline

29. Noar SM, Chabot M, Zimmerman RS. Applying health behavior theory to multiple behavior change: considerations and approaches. Prev Med. 2008;46(3):275280. CrossRef. Medline

30. Kazaura MR, Masatu CM. Sexual practices among unmarried adolescents in Tanzania. BMC Public Health. 2009;9:373. CrossRef

31. Masatu MC, Kazaura MR, Ndeki S, Mwampambe R. Predictors of risky sexual behavior among adolescents in Tanzania. AIDS Behav. 2009;13(1):94-99. CrossRef. Medline

\section{Peer Reviewed}

Competing Interests: None declared.

Received: 23 Jun 2017; Accepted: 4 Aug 2017

Cite this article as: Lyamuya JE, Niau B, Damian DJ, Mtuy TB. Sociodemographic and Other Characteristics Associated With Behavioural Risk Factors of HIV Infection Among Male Mountain-Climbing Porters in Kilimanjaro Region, Tanzania. East African Health Res J. 2017;1 (2):130-137. https://doi.org/10.24248/EAHRJ-D-17-00259

(C) Lyamuya et al. This is an open-access article distributed under the terms of the Creative Commons Attribution License, which permits unrestricted use, distribution, and reproduction in any medium, provided the original author and source are properly cited. To view a copy of the license, visit http://creativecommons.org/licenses/by/ 3.0/. When linking to this article, please use the following permanent link: https:// doi.org/10.24248/EAHRJ-D-17-00259 